\title{
A Normative Review on Non-Invasive Prenatal Diagnosis (NIPD): Focusing on the German Discussion on PrenaTest ${ }^{\oplus}$
}

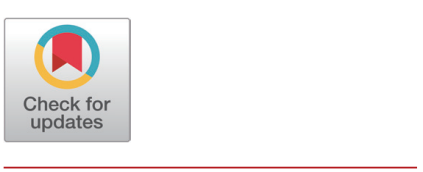

Received: March 11, 2021

Revised: April 24, 2021

Accepted: May 23, 2021

${ }^{+}$Corresponding author

Na-Kyoung Kim

Department of Law, Sungshin Women's

University, Seoul 02844, Korea.

Tel: +82-2-920-7459

E-mail: nakyoungkim@sungshin.ac.kr

Copyright (c) 2021 The Korean Society of Developmental Biology.

This is an Open Access article distributed under the terms of the Creative Commons Attribution Non-Commercial License (http://creativecommons.org/licenses/ by-nc/4.0/) which permits unrestricted non-commercial use, distribution, and reproduction in any medium, provided the original work is properly cited.

ORCID

Na-Kyoung Kim

https://orcid.org/0000-0002-0961-5875

\section{Conflict of interests}

The author declares no potential conflict of interest.

Acknowledgements

This work was supported by the Sungshin University Research Grant of 2019.

Authors' contributions

The article is prepared by a single author.

Ethics approval

This article does not require IRB/IACUC approval because there are no human and animal participants.

\author{
Na-Kyoung Kim \\ Department of Law, Sungshin Women's University, Seoul 02844, Korea
}

\section{Abstract}

This article aims to introduce German discussion on the approval of the non-invasive prenatal diagnosis (NIPD), which started with the development of PrenaTest ${ }^{\circledR}$ by LifeCodexx AG. The discussion started with the concern that the non-invasive nature of NIPD, such as PrenaTest ${ }^{\circledR}$, may rapidly expand the use and scope of similar tests, thus leading to a new era of eugenics. Based on this concern, the need for clear clinical guidelines on specific indications for NIPD has been suggested. Along the same line, it was discussed whether PrenaTest ${ }^{\circledR}$ is against the Basic Law prohibiting discrimination on grounds of disability and whether the test is outside the scope of the purpose of gene testing limited by Genetic Diagnosis Act. Through such discussion, the Federal Ministry of Health of Germany established the preconditions for inclusion of NIPD in the German public health insurance system. For this, the German motherhood guideline was amended and the information for the insured persons provided to pregnant women was included in the amended guideline. Such discussion made in Germany provides insight on which points should be considered when various gene testings are accepted in Korea, in which genetic communication has not been systematized yet. In particular, German counseling system for pregnant women will provide valuable insights for Korea where the direction for regulations on abortion has not been established even after the ruling by the Constitutional Court that charges for abortion are against the constitution.

Keywords: PrenaTest, Non-invasive prenatal diagnosis, Gene testing, Bioethics, Genetic communication, Abortion

\section{INTRODUCTION}

With improvements in genetic science, various types and methods for gene testing have been developed. As such, in some cases, whether new gene testings can be legally or normatively allowed becomes controversial. This manuscript aims to introduce German discussion on the approval of noninvasive prenatal diagnosis (NIPD), which started with the development of PrenaTest ${ }^{\circledR}$ by LifeCodexx AG. In Korea, NIPD is already being used widely in obstetrics and gynecology without much discussion. The lack of discussion of legal legitimacy of NIPD may be attributed to the fact that there are several laws regulating gene testings and that these laws are not organically linked together. More fundamentally, normative discussion of gene testing has not been mature enough to reflect sufficient 
understanding of the essence of gene testing (Kim, 2015). It is not, of course, that normative discussions on the use of NIPD in Korea were absent in the medical community. The Korean Society of Maternal Fetal Medicine has published guidelines regarding NIPD. In accordance with the guideline, clinicians are providing counseling to their patients regarding the use of NIPD and identifying indications. However, such genetic counseling and genetic communication are not yet explicitly regulated by the current Korean law governing gene testing. In this context, introducing the serious discussion that took place in Germany will provide an opportunity to consider which aspects should be discussed in accepting various types of gene testings in Korea. In particular, the German discussion introduced in this manuscript will provide valuable insights for Korea where the direction for regulations on abortion has not been established even after the ruling by the Constitutional Court that charges for abortion are against the constitution.

\section{UNDERSTANDING PRENATEST ${ }^{\circledR}:$ NON-INVASIVE PRENATAL TESTING (NIPD)}

\section{What is PrenaTest ${ }^{\circledR}$ and how has it been developed?}

\section{Significance and characteristics}

PrenaTest ${ }^{\circledR}$ is a fetal gene testing device developed and commercialized by the German company LifeCodexx in 2012. This device was developed to diagnose chromosomal abnormalities, such as Trisomy 21 - also referred to as Down Syndrome - in the fetus by testing the mother's blood. As the test uses the mother's blood to diagnose chromosomal abnormalities in the fetus, the test is considered non-invasive, unlike the previously used tests such as amniocentesis, and has gained interest for its change in paradigm. (Henn \& Schmitz, 2012). PrenaTest ${ }^{\circledR}$ in particular gained interest as the first NIPD device in Europe. The fact that the test is non-invasive means that the test takes place without the risks of complications of invasive testing for the mother and for the fetus. In addition, PrenaTest ${ }^{\circledR}$ may be used to test for trisomy 21 starting from the 9 th gestational week, and the mother can receive the test results in 1 week, unlike previous tests for which 2 weeks of wait were required. In this context, an advantage of PrenaTest ${ }^{\circledR}$ is the reduction in stressful waiting times (Arztebl, 2014). According to section 218a (1) of German Criminal Code (StGB), pregnant women may have abortion without any other condition within 12 weeks of gestation as long as they have had medical counseling as specified by section 219 (2) of StGB. Given this, PrenaTest ${ }^{\circledR}$ allows pregnant women to receive test results within 12 weeks of gestation and helps them to make decisions without limitations from medical-social indications.

\section{The expansion of the test}

At present, PrenaTest ${ }^{\circledR}$ can detect trisomy 21 (Down Syndrome), as well as trisomy 18 (Edwards syndrome), trisomy 13 (Patau syndrome), maldistributions of the sex chromosomes $\mathrm{X}$ and $\mathrm{Y}$ (Turner, triple X, Klinefelter and XYY syndrome), monosomy 21, 18, and 13, trisomies and monosomies of all other chromosomes 1-12, 14-17, 19, 20 and 22, and 22q11.2 microdeletion (DiGeorge syndrome) (Lifecodexx, 2021). If desired, the test can also be used to determine the sex of the fetus. According to the 2013 report by LifeCodexx, the manufacturer of PrenaTest ${ }^{\circledR}$, approximately 6,000 women in Germany had gene testings done using PrenaTest ${ }^{\circledR}$ in 2012, after the test was made available. Of these women, 1/2 were German, 1/4 were Swiss, and 1/4 were from other European countries (Ärzteblatt, 2013). Similar tests have also been developed by other companies in other countries. In addition to Lifecodexx, various companies, including CryoSave, PerkinElmer, Roche 
Diagnostics, Illumina, and NIPD Genetics, manufacture NIPT devices. Furthermore, Genomic Institute from China has also developed NIPT devices, which are available in the European market at affordable prices.

\section{THE DEVELOPMENT PROCESS OF THE DISCUSSION}

The federal government of Germany supported the development of NIPD devices such as PrenaTest ${ }^{\circledR}$, and whether this is legitimate was controversial even before PrenaTest ${ }^{\circledR}$ came into the market (Henn \& Schmitz, 2012). Once PrenaTest ${ }^{\circledR}$ became available in the market, this discussion was expanded to the discussion of approval and scope of use of NIPD, including PrenaTest ${ }^{\circledR}$.

\section{The start of discussion:'Eugenic Concerns' on 'Proliferation of Testing'}

The commercialization and use of PrenaTest ${ }^{\circledR}$ became controversial in Germany mostly because of the concern that the agents and scope of use of the device will expand rapidly owing to its non-invasive nature. For amniocentesis, which is an invasive testing of chromosomal abnormalities in the fetus, the probability of pregnancy loss from the test, along with the probability of chromosomal abnormalities in the fetus, has been an important factor in determining whether prenatal testings can be approved on an individual case in Germany. However, for non-invasive tests, since the probability of pregnancy loss from the invasive nature of the test is no longer an issue, the indications for prenatal testing can be satisfied more easily (Henn \& Schmitz, 2012). Here, some individuals voiced their concern that serious discussion of the conditions for approval and scope of PrenaTest ${ }^{\circledR}$ is necessary. The argument was that the decreased risk of pregnancy loss from the non-invasive nature of the test will expand the use of the test beyond cases with high risk of chromosomal abnormality in the fetus to cases with lower risks (Henn \& Schmitz, 2012). In addition, it is clear that the previously mentioned rapidity of the test will also contribute to the expansion of the test scope. Such concern regarding the indiscreet expansion of the test led to the argument that public strategies should be established to clarify that the use of PrenaTest ${ }^{\circledR}$ does not lead to a new era of eugenics, in order to use PrenaTest ${ }^{\circledR}$ in Germany (Henn \& Schmitz, 2012).

\section{Discussion in the field of Law}

Even before the commercialization of PrenaTest ${ }^{\circledR}$, supporting the development of NIPD was criticized in Germany. In particular, the Federal Government Commissioner for Matters Relating to Persons with Disabilities and LifeCodexx published reviews with opposing views, and they further escalated the discussion of normative approval and scope of use of PrenaTest ${ }^{\circledR}$. The focus of this discussion was whether using PrenaTest ${ }^{\circledR}$ would lead to a new era of eugenics, as was also explained previously. This discussion further led to the discussion of whether PrenaTest ${ }^{\circledR}$ is against the Basic Law for the Federal Republic of Germany prohibiting discrimination on grounds of disability. In addition, whether the test is outside the scope of purpose of gene testing (medical purpose) limited by the German Genetic Diagnostics Act (GenDG) was also discussed.

\section{1) The review by the federal government commissioner}

The Federal Government Commissioner for Matters Relating to Persons with Disabilities commissioned a review of the approval of PrenaTest ${ }^{\circledR}$ to Professor Klaus Ferdinand Gärditz at the University of Bonn, and the review was published in June 2012. According to the review, PrenaTest ${ }^{\circledR}$ was defined as a diagnostic tool that can lead to selective death of the fetus with a possible disability. Using PrenaTest ${ }^{\circledR}$ was thus interpreted as an intentional discrimination of 
persons with disability and not as a case that leads to risks for physical or mental health of the pregnant woman outlined in section $218 \mathrm{a}$ (2) of StGB on abortion. Furthermore, this was also interpreted as discrimination on grounds of disability, which is prohibited by article 3 (3) of the Basic Law for the Federal Republic of Germany (Gärditz, 2012). According to the review, PrenaTest ${ }^{\circledR}$ also violates section 15 (1) of the GenDG which regulates prenatal gene testing. Section 1, section 15 of the GenDG states that prenatal gene testing may be done only for medical purposes. For instance, when PrenaTest ${ }^{\circledR}$ is used to diagnose trisomy 21, the purpose was not interpreted as therapeutic because the condition cannot be treated prior to birth (Gärditz, 2012).

\section{2) The review by LifeCodexx AG}

After the publication of the aforementioned review, another review with opposing views was published. Professor Friedhelm Hufen at the University of Mainz was commissioned by LifeCodexx in 2013 for a review of whether PrenaTest ${ }^{\circledR}$ is against the current law. According to this review, doing gene testing using PrenaTest ${ }^{\circledR}$ alone cannot be interpreted as discrimination on grounds of disability, which is prohibited by article 3 (3) of the Basic Law for the Federal Republic of Germany (Hufen, 2013). In other words, simply using PrenaTest ${ }^{\circledR}$ cannot be seen as disregarding the fetus' life or questioning the inherent value of the fetus. Even if the mother determines early which disability may be present in her future baby and pursues abortion based on this information, this decision is related to the mother's right to know, her life, and her health, which are already acknowledged within the German law system (Hufen, 2013). Furthermore, the review interpreted that gene testings through PrenaTest ${ }^{\circledR}$ satisfied the medical purpose required by section 15 (1) of the GenDG (Hufen, 2013). More specifically, the review interpreted that diagnosis of chromosomal abnormalities was a medical purpose. As such, this review argued that the medical purpose outlined in section 15 (1) of the GenDG should not be interpreted so narrowly as involving only the contribution to treatment and that consideration of abortion by pregnant women should be interpreted as a medical purpose, unlike the review by Professor Klaus Ferdinand Gärditz (Hufen, 2013).

\section{Discussion in the field of Clinical Practice: Request for "Clear Indications"}

As reviewed above, the ethical, normative discussion of NIPD, including PrenaTest ${ }^{\circledR}$, started from the interest in establishing a system to prevent the use of the tests as expression of hatred for disability. In clinical practice, arguments were made for clear definition of the indications for PrenaTest ${ }^{\circledR}$ while differentiating from those for conventional prenatal testing or management. In this context, in 2014, Landesärztekammer Hessen claimed that specific guidelines containing clear indications for NIPD (eine klare Indikationsliste) should be prepared (Ärzteblatt, 2014). A particularly noteworthy concern made by Medical Association of Hessen State (Landesärztekammer Hessen) is that pregnant women may think that the use of NIPD is a part of normal prenatal management if clear criteria for approved use of NIPD are absent. Such concern stems from the belief that it is not valid for an individual to make an easy decision to pursue gene testing to diagnose the fetus' disability without sufficient consideration of various perspectives of opinions surrounding the issue. How this logic has been reflected in the German legal system regarding life that has not been born yet and gene testing will be explored in further detail below.

\section{DECISION OF GERMAN FEDERAL JOINT COMMITTEE (G-BA)}

Although much discussion has been made regarding PrenaTest ${ }^{\circledR}$, including normative discussion 
of its approval, it would have been impractical for Germany to deny using NIPT for prenatal testings given the non-invasive and rapid nature of the test and the growing scope of genetic diseases that can be diagnosed through the test. As such, the discussion regarding PrenaTest ${ }^{\circledR}$ led to the preparation of preconditions to legitimize the use of NIPD and PrenaTest ${ }^{\circledR}$ in diagnosis of trisomy 13, 18, or 21. Since NIPD will be used in the context of obstetrics where pregnant women receive medical services, the discussion regarding NIPD was summarized into the following two issues: Whether the new medical practice should be covered by the statutory health insurance funds (Gesetzliche Krankenversicherung, GKV) and which clinical guidelines should be suggested for the use of NIPD in clinic.

\section{Inclusion of NIPD as a healthcare benefit of GKV}

\section{1) Decision of Federal Joint Committee (G-BA)}

Certain procedures should be followed to include a new medical practice or technology as a healthcare benefit of public health insurance system. In Germany, the basis for establishment of a new medical practice or technology lies in section 91 of German Social Code, Book Five (SGB $\mathrm{V})$. Only when the new practice or technology is evaluated and recommended by the Federal Joint Committee (Gemeinsamer Bundesausschuss: G-BA, 2019) under the statutory supervision of the German Federal Ministry of Health, it can be covered by the statutory health insurance funds (GKV) (Kim, 2009). NIPT is also considered a new testing method defined by section 91 of SGB V. In 2016, an application was made to determine whether the test can be covered by GKV. In order to review the application, G-BA reviewed whether the test satisfies the criteria required for coverage under GKV. According to section 135 (1) of SGB V, in order to be covered by public insurance, the test should satisfy conditions regarding therapeutic utility, medical necessity, and economic feasibility as determined by the current scientific understanding of the medical test. Based on these, in 2019, G-BA determined that using NIPD to confirm the risk of trisomy 13, 18, or 21 can be covered by GKV.

\section{2) Medical necessity}

It is particularly noteworthy from G-BA's decision that it mentioned the process in which a pregnant woman considers and determines the need for prenatal testing in its evaluation of medical necessity of NIPD. G-BA based the medical necessity of NIPD on the invasive nature of other prenatal testings and the high specificity of NIPD, which means that it can reliably produce true negative results (G-BA, 2019). In other words, negative NIPD results decrease the probability that unnecessary invasive tests will be done for the pregnant woman. What is even more important than this explanation is that G-BA clearly specified that the medical necessity of NIPD cannot be determined solely by the size of 'statistical risk' of chromosomal abnormality - trisomy 13,18 , or 21. G-BA stated that the need for NIPD in a pregnant woman can be determined through communication with her physician regarding pregnancy and delivery, including the probability of genetic risks in the fetus. In the process of such communication, the pregnant woman considers whether pregnancy and its outcome may severely impair her own mental health or increases her burden. If the pregnant woman did not sufficiently consider whether such impairment or burden is unexpectedly serious and exceptional, the use of NIPD cannot be legitimized only based on the statistical risk of trisomy.

\section{Specification by the motherhood guideline (Mutterschaft Richtlinien)}

Section 92 of SGB V specifies that G-BA should determine the guidelines necessary to 
guarantee that medical practices covered by GKV offer sufficient, appropriate, and economical benefit for the insured. G-BA determined that the existing motherhood guideline (Mutterschaft Richtlinien), which is the existing clinical guideline on prenatal testings established based on Nr.4, section 92 (1) of SGB V, should be amended be first. This is because the motherhood guideline (Mutterschaft Richtlinien) is also applicable for NIPD if is specified as a GKV benefit. As such, the motherhood guideline (Mutterschaft Richtlinien) was amended on September 19, 2019. In addition, G-BA determined that the new guideline should clearly outline which information should be provided to pregnant women to guarantee a thorough communication with her physician, which is needed to determine the medical necessity of the test. Based on this decision, the information for the insured pregnant women, which will be used officially, was determined on April 22, 2021.

\section{1) Basic principles for explanation and counseling}

NIPD is a non-invasive prenatal testing and a gene testing. Therefore, the German motherhood guideline (Mutterschaft Richtlinien) clearly specifies that sufficient explanation and counseling should be provided to the patient receiving gene testing, as outlined by the GenDG, and suggests the specific methods of explanation and counseling. Regarding explanation and pre-test counseling, it is particularly important that a reasonable time for reflection should be provided after explanation of the gene testing for the pregnant woman or counseling with the woman such that she can decide whether she agrees with the explanation and will pursue the test (G-BA, 2019). This guarantees the fact that the pregnant woman's decision regarding NIPD has been made upon sufficient consideration of various factors and also guarantees that the decision does not mean simple rejection or hatred for disability, as was mentioned previously (Kim, 2015). The guideline in particular specifies that the counseling should be open-ended and guarantees the pregnant woman's right not to know the NIPD results (G-BA, 2019). By doing so, the guideline clarifies that a pregnant woman may not necessarily pursue gene testing through NIPD or disapprove the life of the fetus based on the test results simply because there is a high risk of genetic abnormality in the fetus.

\section{2) Guaranteeing the possibility of exchange of various views}

Genetic counseling regarding NIPD is provided by a physician with qualifications specified by the GenDG (Kim, 2016). However, counseling with a physician alone cannot guarantee that the pregnant woman reflected sufficiently on various perspectives surrounding gene testing. Therefore, the motherhood guideline (Mutterschaft Richtlinien) specifies that counseling with a physician should offer detailed explanation of 'psychological and social questions' about the test and 'resources for physical and psychological burden' (G-BA, 2019). In particular, in order to solve the issue about indiscreet rejection and hatred for disability, which was an issue of interest in normative discussion about the approval of NIPD including PrenaTest ${ }^{\circledR}$, it is important to guarantee the opportunity to hear from persons with trisomy or their parents (Kim, 2007). The motherhood guideline guarantees this process as follows: "Pregnant women should be offered an opportunity to counsel individuals who are used to life with trisomy from their own experience" (G-BA, 2019). Through this process, pregnant women can consider the various aspects of life with trisomy - in other words, difficulties as well as rich life experiences (Kim, 2007).

\section{Information for the insured pregnant women}

As mentioned above, the motherhood guideline amended to include NIPT as a benefit under GKV includes the information that should be provided to pregnant women during counseling - the information for the insured persons. The information for the insured persons was prepared by the 
Institute for Quality and Efficiency in Health Care (Institut für Qualität und Wirtschaftlichkeit im Gesundheitswesen, IQWiG), which has a basis according to section 139a (1) of SGB V, upon the request from G-BA, and it was approved by G-BA on April 22, 2021. With the preparation of official, standardized set of information for the insured persons, a safety measure was prepared to guarantee a thorough discussion of important aspects that should be mentioned in the aforementioned counseling (and sometimes explanation) process as well as to guarantee the correct direction of the counseling. The information for the insured persons specifies that the pregnant woman should make the decision 'with' her physician in that NIPD must be a significant factor in her personal situation in order for it to be covered under GKV. Moreover, it clarifies that 'detailed' counseling from a physician should precede NIPD. In addition, the information specifies that prenatal testing, including NIPD, remains a free choice of a pregnant woman and introduces organizations that can offer other information or support for the pregnant woman to make decisions regarding prenatal testing.

\section{CONCLUSION}

In Korea, NIPD is already being used widely in clinical medicine without discussion of whether it is legitimate to use NIPD in clinic or to cover it under the National Healthcare Insurance. In order to introduce a new medical practice using a new device, the device should be approved as a medical device by the Korean Ministry of Food and Drug Safety. In order for the new device to be approved as a medical device, the safety and efficacy of the device should be evaluated by the Center for New Health Technology Assessment at the National Evidence-Based Healthcare Collaborating Agency. In addition, in order for the medical practice utilizing this device to be covered under the National Health Insurance, it should be listed as a medical care expense according to the National Health Insurance Act and related laws. However, for the case of gene testing, blind spots where these regulations do not necessarily apply exist. This is because gene testings are governed by another regulation under the Bioethics and Safety Act (BioAct). According to the act, in order for a private institution that is not considered a medical institution to perform gene testing, the institution should declare the testing equipment and employees required for a gene testing institution to the Minister of Health and Welfare as well as the items that are being tested (section 49(1) of BioAct). In other words, when a non-medical institution performs gene testing, it only needs to declare the items for the new gene testing even if the test has a medical purpose, which is different from the case for tests done at medical institutions. However, the test items should not be those that are positively prohibited by section 50 of BioAct, and the tests should be done upon the request of a medical institution when the tests are being used for prevention, diagnosis, or treatment of a disease (Nr.1, section 50(3) of BioAct). Based on these regulations, in the scope of medical practice, not medical care expenses, medical institutions often request NIPD to be done at nonmedical gene testing institutions.

In this legal blind spot where medical validity is not tested, NIPD has been introduced to clinical medical practice in Korea mostly through gene testing institutions rather than medical institutions. Of course, the introduction of NIPD to clinical medicine is not an issue itself. However, since NIPD leads to termination of pregnancy for disability of the fetus in many cases, it is regrettable that there was no normative discussion on the procedures of the test. The lack of normative discussion cannot be attributed only to the different regulations applicable to gene testing done at a non-medical institution and those done at a medical institution. Regarding gene testing, Korea lacks regulations on genetic communication that sufficiently reflect the essence of gene testing (Kim, 
2015). Gene testing consists of analysis and interpretation. Here, if genetic communication, which supports the patient to have sufficient understanding of the inherent incompleteness of the analysis and the broad spectrum of interpretation and to accept the test results into their life, is absent, the normative legitimacy of the gene testing cannot be guaranteed in its entirety (Kim, 2015). Nevertheless, in the current Korean legal system about gene testing, such genetic counseling is not specified (Kim, 2016). Therefore, at least officially, the process in which the pregnant woman reflects sufficiently on various aspects around disability diagnosed through the test results is not guaranteed. In addition, official support for the pregnant woman's planning of her life based on the test results is also not guaranteed by law. In this context, it is difficult to legitimize the decision for abortion based on NIPD, as can also be seen in the German discussion of PrenaTest ${ }^{\circledR}$. For this reason, the German discussion of PrenaTest ${ }^{\circledR}$ provides insights on improvement of the current Korean legal system on gene testings and NIPD. First, it is necessary to remove the legal blind spot in which the regulation differs, and sufficient verification of medical validity is not performed depending on the agent of gene testing, through a single, unified legal system on gene testing, as is the case in Germany. Second, laws on gene testing should systematize a procedure for genetic communication for the patient to understand gene testing, and genetic counseling should be systematized first for this. Third, since NIPD is directly related to pregnancy and delivery, genetic counseling as well as family planning counseling should be provided to pregnant women. Fourth, such counseling for pregnant women should be reflected in amendments of Korean criminal law regarding abortion. At least these aspects should be considered to guarantee the legitimacy of Korean legal system on gene testing, prenatal testing, and pregnancy termination.

\section{REFERENCES}

Arztebl D (2014) Genanalysen in der schwangerenvorsorge: Keine zeit zum nachdenken. Dtsch Arztebl 111:A1806, B1550, C1482.

Ärzteblatt D (2013) 6.000 Down-Syndrom-Bluttests im ersten Jahrw. Available from: https:// www.aerzteblatt.de/treffer? mode $=$ s\&wo=1041\&typ=1\&nid=55602\&s=prenatest. Accessed at May 1,2021.

Ärzteblatt D (2014) Kammer Hessen fordert klare Richtlinien für genetische Pränataltests. Available from: https://www.aerzteblatt.de/treffer?mode=s\&wo=1041\&typ=1\&nid=58105\&s=prenatest. Accessed at May 1, 2021.

Gärditz KF (2012) Gutachtliche Stellungnahme zur Zulässigkeit des Diagnostikprodukts "PrenaTest". Beauftragten der Bunderegierung für die Belange behinderter Menschen, Bonn, Germany.

Gemeinsamer Bundesausschuss [G-BA] (2019) Zusammenfassende dokumentation: Beratungsverfahren methodenbewertung mutterschafts-richtlinien. Available from: https:// www.g-ba.de/downloads/40-268-6008/2019-09-19_Mu-RL_NIPT_ZD.pdf. Accessed at May 1,2021.

Henn W, Schmitz D (2012) Pränataldiagnostik: Paradigmenwechsel. Deutsches Ärzteblatt 109:A1306, B1129, C-1111.

Hufen F (2013) Zur verfassungrechtlichen Beurteilung frühzeitiger pränataler Diagnostik. Available from: https://docplayer.org/15811184-Zur-verfassungsrechtlichen-beurteilungfruehzeitiger-praenataler-diagnostik.html. Accessed at May 1, 2021.

Kim NK (2007) Termination of pregnancy on the ground of fetal disability. J Crim Law 19:127165 . 
Kim NK (2009) A note on the normative control method of medical practice: Justification of voluntary non-health care benefits control in the light of the German medical insurance system. Hum Right Justice 392:73-89.

Kim NK (2015) Hermeneutical understanding of disabilities and law: Legal policy of gene testing in Korean Bioethics and Biosafety Act.J Korean Bioeth Assoc 16:67-84.

Kim NK (2016) Understanding the legal structure of german human gene testing act.J Korean Soc Law Med 17:85-124.

LifeCodexx. (2021) PrenaTest ${ }^{\circledR}$. Available from: https://lifecodexx.com/en/expectant-mothers/ prenatest/. Accessed at May 1, 2021. 
